\title{
Physiological and growth responses of two wheat (Triticum aestivum L.) varieties inoculated with a new strain of Bacillus siamensis under Cadmium (Cd) stress
}

Imran Khan

Sichuan Agricultural University - Chengdu Campus

Huang Linkai ( $\sim 3484861784 @ q q . c o m$ )

Samrah Afzal Awan

Sichuan Agricultural University - Chengdu Campus

Abd ur Rehman

University of Arid Agriculture

Muhammad Ali Raza

Sichuan Agricultural University - Chengdu Campus

Muhammad Rizwan

Government College University Faisalabad

Aaqil Khan

Sichuan Agricultural University - Chengdu Campus

Rezwan Tariq

Chinese Academy of Agricultural Sciences

Nosheen Akhtar

University of Arid Agriculture

Ghulam Abbas Shah

University of Arid Agriculture

Muhammad Ansar

University of Arid Agriculture

Majid Sarwar

Higher Education Department.

Marian Brestic

slovak university of agriculture, Nitra, Slavakia

Nosheen llyas

University of Arid Agriculture

Original article 
Keywords: cadmium, wheat, productivity, biomass, microorganisms

Posted Date: April 23rd, 2020

DOI: https://doi.org/10.21203/rs.3.rs-22644/v1

License: (c) (i) This work is licensed under a Creative Commons Attribution 4.0 International License. Read Full License 


\section{Abstract}

Bioavailability of cadmium (Cd) metal in the soils due to scarcity of good quality water and industrial waste could be the major limiting factors negatively influencing the growth and yield of crops needs prompt solution to fulfil the requirement of food for increasing world population. In the recent time, variable range of plant growth promoting rhizobacteria (PGPR) are being used on large scale in agriculture to reduce the risk of abiotic stresses on plants and increase crop productivity. Among them, the Bacillus siamensis has a huge potential to enhance the plant tolerance against abiotic stress but limited evidences are reported about the putative role of B.s in crop plants under heavy metal stress. The current study was aimed to investigate the potential of a new metal tolerant strain of B.s on two wheat (Triticum aestivum L.) varieties (NARC-2009 and NARC-2011) grown in Cd contaminated soil at different treatments i.e $\mathrm{Cd}(0,20,30$ and $50 \mathrm{ppm})$ and $\mathrm{Cd}(0,20,30$ and $50 \mathrm{ppm})+$ B.s. Our results depicted that $\mathrm{Cd}$ stress decreased the wheat growth related attributes, biomass, and photosynthetic parameters (Chlorophyll $\mathrm{a}, \mathrm{b}$ and $\mathrm{a}+\mathrm{b}$ ) which increased in both wheat varieties upon inoculation with B.s. Moreover, $\mathrm{Cd}$ stress caused significant membrane damage and negatively affected the water content, water potential, and osmotic potential of leaf. However, PGPR considerably increased the soluble sugars to reduce the $\mathrm{Cd}$ toxicity. Overall, the plants inoculated with B.s enhanced their tolerance index of root and shoot and found better in NARC-2009 than NARC-2011. Therefore, microorganisms efficiently increase the plant growth by reducing the metal toxicity.

\section{Introduction}

Agriculture is considered as the big source of economy and basic livelihood of people in several countries of the world (Mishra et al. 2014). Agriculture as a pillar in food industry is estimated to provide food for world's increasing population (FAO and http://faostat.fao.org/). The global agricultural regions including cereals especially wheat are facing a wide spectrum of challenges, such as biotic and abiotic stresses under normal condition (Rizwan et al. 2016a). Among different type of environmental stresses, the heavy metal stress is getting more focus and becoming a serious environmental issue from last few decades (Hussain et al. 2018). The cadmium (Cd) is thought to be very toxic entity, non-biodegradable, bioaccumulative and a major wheat yield limiting factor (Shoeva and Khlestkina 2018). Cd enters the environment via geogenic and anthropogenic sources such as fertilizer, sewage slough dispersal, industrial waste, electroplating and atmospheric deposition (Rizwan et al. 2018). The Cd firstly accumulated by root directly from the soil and caused reduction in root length, then transferred to aerial parts where it reduced the photosynthesis and resulted in stunted growth and reduced yield (Rizwan et al. 2017). The Cd led to the excessive production of ROS caused oxidative damage and negatively affected the antioxidant defence system of plants (Hussain et al. 2018).

The Cd has high mobility and bioavailability, and enters the food chain via consumption of different vegetables, cereals and cereal grains obtained from cd contaminated soil due to its efficient mobility and bioavailability (Rizwan et al. 2016b). The wheat (Triticum aestivum L.) is utilized as staple food by more than $50 \%$ population of the world and an important cereal crop worldwide (FAO and 
http://faostat.fao.org/). The demand for food from wheat is increasing globally day by day and requirement of wheat to feed the increasing population is getting more attention (Curtis and Halford 2014). Wheat has greater potential to accumulate $C d$ in its various parts as compared to other cereals, resulting the higher Cd compartmentalization in wheat (Naeem et al. 2016). However, the accumulation of $\mathrm{Cd}$ varies with wheat cultivars, type of soil and soil contamination level. But the uptake and transfer of $\mathrm{Cd}$ from root to shoot depends upon the xylem and phloem loading (Harris and Taylor 2013). Therefore, it is extremely important to reduce the intake and transfer of $\mathrm{Cd}$ to aerial parts which is an ultimate risk to humans and other living organisms that consume wheat (Keller et al. 2015).

Plant growth promoting rhizobacteria (PGPR) increase the root development which reflects the accumulation of more water and essential nutrients to a suitable concentration and consequently improve the plant growth by enhancing the photosynthetic apparatus efficiency, linked with chlorophyll concentration and PSII functionality (Mesa-Marín et al. 2018). PGPR are currently used to immobilize and resist the metal toxicity and improve the plant growth by reducing the heavy metal uptake and accumulation within plants (Mallick et al. 2018). PGPR increase the plant growth by restricting the heavy metal accumulation in roots and stopping its transfer toward aerial parts through shoot (Mesa et al. 2015). The higher uptake of heavy metals negatively impacted the photosynthetic carbon consumption during respiration by altering the mitochondrial and electron transport chain configuration however, inoculation with PGPR recovered the plant metabolism by limited translocation of metals in the roots of plants (Mesa-Marín et al. 2018). Previously, it has been reported that Bacillus megaterium limited the intake and transfer of $\mathrm{Ni}$ and improved the growth of Sorghum halepense, Luffa cylindrica and Brassica juncea (Rajkumar et al. 2013). Neorhizobium huautlense considerably increased the growth and biomass production of Chinese cabbage and radish by reducing the uptake of $\mathrm{Cd}$ and lead (Pb) (Wang et al. 2016). Enterobacter species has ameliorated the growth of rice seedlings with respect to germination potential, biomass and chlorophyll contents by reducing the Cd stress invitro (Pramanik et al. 2018). Moreover, PGPR provide better resistance to heavy metal infected sites in plants by the synthesis of plant hormones such as indol acetic acid (IAA) and gibberellins. These also facilitate the production of siderophores and solubilising phosphate that increase the plant growth and physiological profile by minimizing the translocation of heavy metals within plants (Gupta et al. 2018).

However, it is needed to reduce the harmful impact of heavy metals especially $\mathrm{Cd}$ in crop plants while stimulating the plant growth. The present study explored the advantageous role of seed inoculation with Bacillus siamensis strain in two wheat varieties with respect to their growth, photosynthetic attributes, biomass and water status of leaf tissues in Cd contaminated soil. To the best of our knowledge, this is the first report which describes the efficient role of the new strain of Bacillus siamensis against Cd stress in wheat plants. This study may provide new strategies to increase cereal crop production by ameliorating heavy metal toxicity in plants with application of PGPR.

\section{Materials And Methods}

\subsection{Pot Experiment}


A pot experiment was performed in the greenhouse of the department of botany, Arid agriculture university, rawalpindi under natural conditions at $28 / 20^{\circ} \mathrm{C}$ day and night temperature with $65 \pm 6 \%$ relative humidity. The seeds of two wheat (Triticum aestivum L.) varieties (NARC-2009 and NARC-2011) were obtained from National Agriculture Research Centre (NARC) Islamabad. The seeds was surface sterilized with sodium hypochloride ( $2.6 \%$ active chloride) for three mins then properly washed with double distilled water. Afterwards, the half of the seeds of each wheat variety were inoculated with Bacillus siamensis (strain no. MH559649 obtained from the department of botany with adjusted concentration of bacteria at $1.2 \times 10^{8}$ cells $/ \mathrm{ml}$ ) for 24 hours at room temperature. Then the PGPR inoculated wheat seeds were air dried. The PGPR inoculated seeds were sown in twenty four (24) pots and rest of twenty (24) pots had un-inoculated seeds (pre-treated with distilled water over night). Eight seeds of each wheat variety were sown in each plastic pot containing $5 \mathrm{~kg}$ air-dried loamy soil (1:3) of sand and silt respectively. The soil analysis has given in Table.1. Before sowing the seeds, soil was subjected to $\mathrm{Cd}$ stress $\left(\mathrm{CdCl}_{2} \cdot 2 \mathrm{H}_{2} \mathrm{O}\right)$ as $(\mathrm{Cd}-0, \mathrm{Cd}-20, \mathrm{Cd}-30$ and $\mathrm{Cd}-50 \mathrm{mg} / \mathrm{kg}$ soil) and the remaining four treatments as given as (Cd-0, Cd-20, Cd-30 and Cd-50 mg/kg soil) + PGPR (Bacillus siamensis) that gave total of 8 treatments. Field capacity was maintained at $70 \%$ throughout the experiment. After 10 days of sowing, wheat plants of each pot were subjected to thinning and five wheat plants were kept in each pot and the experiment was carried out with three replicates of each treatment in a completely randomized design (CRD). Throughout the experimental period, wheat plants were protected under greenhouse to avoid rain. At 30 days after sowing (DAS), the plants were collected for further analysis.

\subsection{Growth parameters}

At 30 DAS, immediate after plant harvesting, the length of root and shoot, leaf area and fresh weight were measured by using meter rod and electrical balance. These parameters were recorded for each pot and the mean values were determined in triplicate. After that remove the contamination by washing plant roots with distilled water and oven dried at $70{ }^{\circ} \mathrm{C}$ to measure constant dry weights and weighed (Rizwan et al. 2019).

\subsection{Measurement of Chlorophyll contents}

For chlorophyll content, the fresh leaf samples were extracted with $85 \% \mathrm{v} / \mathrm{v}$ acetone at $4{ }^{\circ} \mathrm{C}$ for 24 hours under dark conditions. Afterwards, the ready sample's wavelength was measured at 470, 647 and $664 \mathrm{~nm}$ by using a spectrophotometer. The chlorophyll contents were calculated according to method described by (Lichtenthaler 1987).

\subsection{Determination of total soluble sugars content}

The leaf tissues were taken into $10 \mathrm{ml}$ centrifuge tube with $80 \%$ ethanol $(5 \mathrm{ml})$. The reaction mixture was incubated in water bath with shaking for $30 \mathrm{~min}$ at $80^{\circ} \mathrm{C}$ and centrifuged for $5 \mathrm{~min}$ at $4000 \mathrm{rpm}$ to get the supernatants. Pallets were treated with $80 \%$ ethanol for two more extractions. Supernatants were collected and diluted with $80 \%$ ethanol and mixed to form whole volume upto $25 \mathrm{ml}$, and kept at $-20{ }^{\circ} \mathrm{C}$ for further analysis. The total soluble sugars were measured by following the method of (Seifter et al. 1950). 


\subsection{Determination of Membrane Stability Index (MSI)}

The leaf from each sample was cut into small pieces $(100 \mathrm{mg})$ and washed with double distilled water. Afterwards, leaf pieces were inserted in test tubes and placed in a water bath at $40^{\circ} \mathrm{C}$ for $30 \mathrm{~min}$. Then, $\left(\mathrm{C}_{1}\right)$ electric conductivity was measured by using EC meter. Again the samples were placed in a water bath at $100^{\circ} \mathrm{C}$ for ten mins and electric conductivity $\left(C_{2}\right)$ was measured. the MSI was calculated according to formula given by (Sairam et al. 2005).

Membrane stability index $=\left[1-\mathrm{C}_{1} / \mathrm{C}_{2}\right] \times 100$

\subsection{Determination of Osmotic and Water Potential}

To calculate the osmotic potential and water potential under water deficit conditions, the pressure chamber was utilized with pressure measurement value of 6.0 MPa (Turner and Begg 1981). A fully expanded leaf was taken to determine the osmotic potential with vapour pressure osmometer. Osmotic potential was obtained by measuring the difference at $100 \%$ relative water content with water scarcity relative water content. According to the (Turner 1986), the equation was used to calculate osmotic potential;

OP100 = OP (RWC-Assumption of apoplastic water)/100 - Assumption of apoplastic Water OP stands for osmotic potential and RWC stands for the relative water content of the leaf.

\subsection{Relative water content and tolerance index of root and Shoot}

To measure the leaf relative water content (LRWC), the procedure given by (Turk and Erdal 2015) was used. Immediate after harvesting the plants, fresh weight (FW) of seventh leaf of wheat plant was calculated. Then leaf was cut into segments and dipped in distilled water over night to get the turgid weight (TW). Afterwards, the samples were subjected to an oven at $70 \mathrm{C}$ and measured the dry weight (DW). The RWC was measured according to given formula as;

$R W C=[(F W-D W) /(T W-D W)] \times 100$.

To find out the tolerance index of root and shoot, the formula of (Turner and Marshall 1972) was used as given below;

Tolerance Index $=\frac{\text { Mean length in Cd solution }}{\text { Mean length in control }}$

\subsection{Statistical analysis}


The analysis of data was accomplished by using SPSS. The significance of data was analysed with oneway analysis of variance ANOVA. All values are given as mean of three replicates. The $5 \%$ level of probability was used to compare the mean with least significance difference (LSD) test.

\section{Results}

\subsection{Plant morphological traits and leaf area}

The results of current study depicted that inoculation with B.s positively improved the growth of both wheat varieties grown in Cd contaminated soil (Figure.1 and 2). At 30 DAS, the plants inoculation with B.s significantly increased the morphological traits such as length of root, shoot and leaf area as compared to non-treated plants. In NARC-2009, the root length and shoot length were increased by $15 \%$ and $13 \%$ at B.s alone, over the control, respectively. While on the other hand, $\mathrm{Cd}$ treatment decreased the root length by $54 \%$ and shoot length by $35 \%$, at the highest level ( $50 \mathrm{ppm}$ ) over the control (Figure.1A and B). In contrast to NARC-2009, the NARC-2011 decreased the root- and shoot length by $55 \%$ and $43 \%$ at $50 \mathrm{ppm}$ Cd over the control. While B.s improved the root length by $11 \%$ and shoot length by $7 \%$ over the control, in NARC-2011. Pre-treatment with B.s increased the leaf area by $12 \%$ and $14 \%$ in NARC-2009 and NARC2011 over the control of both varieties, respectively. Conversely, the $\mathrm{Cd}$ application reduced the leaf area by $10 \%$ and $9 \%$ at $50 \mathrm{ppm}$ Cd as compared to control of NARC-2009 and NARC-2011 respectively (Figure.2A). In both wheat varieties all tested levels of cadmium considerably decreased the morphological traits however, the application of B.s mitigated the effect of $\mathrm{Cd}$ and improved the wheat growth. Similar trend was notice with respect to membrane stability index in both wheat varieties treated with Cd stress. The maximum decrease in MSI was 34\% and 37\% in NARC-2009 and NARC-2011 at the highest level $\mathrm{Cd}-50 \mathrm{ppm}$ whereas, B.s ameliorated the injury caused by $\mathrm{Cd}$ toxicity and improved the MSI by $11 \%$ and $7 \%$ respectively, over the control (Figure.2B).

\subsection{Total biomass accumulation}

Different levels of Cd negatively impacted the total biomass accumulation however, the application of B.S lessened the harmful effects of $\mathrm{Cd}$ and enhanced the biomass production when compared with nontreated plants in both wheat varieties (Figure.3). Cd treatment at $50 \mathrm{ppm}$, decreased the total biomass (fresh and dry) accumulation by $35 \%$ and $40 \%$ in the plants of NARC-2009, and $33 \%$ and $45 \%$ in NARC2011 over the control of both varieties, respectively at 30 DAS. In contrast, the highest biomass (fresh and dry) accumulation was $15 \%$ and $49 \%$ in the plants of NARC-2009 treated with B.s alone over the control (Figure.3A and B).

However, in NARC-2011, the maximum accumulation of biomass (fresh and dry) was $17 \%$ and $37 \%$ in the plants inoculated with the B.s over the control. On contrary, at highest level of Cd-50 ppm, the maximum reduction in fresh and dry biomass was $33 \%$ and $45 \%$ over the control, respectively. In addition, the NARC2009 significantly enhanced the total biomass accumulation as compared to NARC-2011, inoculated with B.s and grown in Cd contaminated soil. 


\subsection{Chlorophyll content}

The plants inoculation with B.s enhanced the chlorophyll contents and improved the MSI of both wheat varieties grown in Cd contaminated soil (Figure.4). In NARC-2009, the Cd treatment at 20, 30 and $50 \mathrm{ppm}$ decreased the chlorophyll a (Chl a) by $25 \%, 27 \%$, and $50 \%$, chlorophyll b (Chl b) by $18 \%, 39 \%$ and $56 \%$, and chlorophyll $\mathrm{a}+\mathrm{b}(\mathrm{Chl} \mathrm{a}+\mathrm{b})$ concentrations by $22 \%, 32 \%$ and $53 \%$ over the control, respectively. However, the plants pre-treated with B.s increased the chl $\mathrm{a}$, chl $\mathrm{b}$ and $\mathrm{Chl} \mathrm{a}+\mathrm{b}$ concentrations by $2 \%, 14 \%$ and $7 \%$ over the control, respectively (Figure.4A, B and C). Whereas, the $\mathrm{Chl} a$ : $\mathrm{b}$ ration was decreased in B.s treatment as compared with all Cd treated levels (Figure.4D). However, more decrease in Chl contents were observed in NARC-2011 due to Cd toxicity as compared to NARC-2009. Results showed that $28 \%$, $45 \%, 48 \%$ decrease in $\mathrm{Chl} \mathrm{a}, 28 \%, 47 \%, 65 \%$ in $\mathrm{Chl} \mathrm{b}$ and $27 \%, 46 \%, 55 \%$ in $\mathrm{Chl}$ a $+\mathrm{b}$ was noticed in plants exposed to $\mathrm{Cd}$ at 20,30 and $50 \mathrm{ppm}$ over the control. In addition, B.s application improved the $\mathrm{Chl} \mathrm{a}, \mathrm{b}$ and $\mathrm{a}+\mathrm{b}$ contents by $8 \%, 17 \%, 12 \%$ over the control.

\subsection{Total soluble sugars}

The Cd treatment negatively affected the total soluble sugars in both wheat varieties at all levels however, the application of B.s enhanced the soluble sugars and improved the plant growth significantly (Figure.5). In the wheat plants, the maximum reduction in soluble sugars was $35 \%$ and $32 \%$ at $\mathrm{Cd}-50 \mathrm{ppm}$ while the maximum production was $13 \%$ and $14 \%$ when plants were inoculated with B.s for NARC-2009 and NARC2011, respectively.

\subsection{Determination of Water Potential and Osmotic potential}

The $\mathrm{Cd}$ at different levels of drastically effected the water potential and osmotic potential however, the seed inoculation with B.s positively impacted the water and osmotic potential in wheat as compared to non-treated plants in both varieties (Figure.6). The $\mathrm{Cd}$ at highest level $50 \mathrm{ppm}$ the values for potential and osmotic potential were 3.03 and $4.94-\mathrm{MPa}$ whereas, the application of B.s improved the water potential and osmotic potential as 0.95 and 2.7 - MPa, respectively in NARC-2009. Similar results were observed in NARC-2011, the $C d$ at 50 ppm negatively affected the water and osmotic potential as 3.15 and $5.09-$ MPa, improved with B.s application as 1.64 and $3.23-$ MPa respectively (Figure.6A and B).

\subsection{Leaf Relative water content (LRWC) and tolerance index}

The application of B.s positively impacted the LRWC and tolerance index of both wheat varieties under Cd stress (Figure.7 and 8). The maximum increase in LEWC was noted $94 \%$ in NARC-2009 and $90 \%$ in NARC-2011 after inoculation with B.s alone. In contrast, the maximum reduction in LRWC was recorded at the highest level of Cd-50 ppm. At highest level of Cd-50 ppm, the LRWC was noted as $70 \%$ and $65 \%$ in NARC-2009 and NARC-2011, respectively. Moreover, the tolerance index was found more in NARC-2009 as compared to NARC-2011 which is shown in the (Figure.8A and B) as root and shoot tolerance index separately.

\section{Discussion}


The current study depicted that Cd treatment impaired the growth of wheat plants with respect to all morphological traits and $\mathrm{Cd}$ had severe impact at highest level of Cd-50 ppm (Figure.1 and 2). In contrast, the seed inoculation with B.s positively affected the plant growth profile exposed to $\mathrm{Cd}$ stress. The detailed molecular mechanism of $\mathrm{Cd}$ toxicity is poorly understood yet however, few researchers explained the damaging effects that $\mathrm{Cd}$ may destroy the soil microbial communities, reduce the water and nutrients uptake, and impair the cell division and elongation process ultimately decrease the crop growth (Khanna et al. 2019). Our results reaffirm the findings of (Ahmad et al. 2015), who described a significant reduction in root and shoot length of B.juncea exposed to Cd stress. In addition, the limited growth of root and shoot and leaf chlorosis on exposure to heavy metals has been suggested in previous studies (Hussain et al. 2019). The decline in root and shoot elongation is directly associated with the inhibition of root and shoot metabolism and ultimately affected the overall plant growth (Khanna et al. 2019). Seed inoculation with microbial strain (PGPR) considerably improved the wheat growth in the current study (Figure.1). Microorganisms facilitate the plant growth and development, and increase the supply of phosphate through siderophores formation, root hairs growth, and hormonal stimulation that reduce the heavy metal translocation (Gupta et al. 2018). PGPR induces changes in metabolic activities involve in solubilization and mineralization of organic phosphorous. These metabolic activities helps in the efflux of proton and other various anions, and then phosphatase enzymes release that enables the hydrolysis and mineralization of phosphorus (Ahemad and Kibret 2014). (Liu et al. 2018) reported the microbial treatment enhanced the growth of maize plant under Cd stress.

Moreover, the Cd stress declined the biomass (fresh and dry) accumulation in both wheat varieties as shown in (Figure.3). Similar findings were achieved by (Verma et al. 2008) in B. juncea under Cd stress. A significant decrease in the plant biomass under Cd stress could be due to its harmful impact on root and root hair development, essential nutrient uptake via roots, chlorophyll biosynthesis in leaf, photosynthesis, less water and more Cd accumulation in different organs of plants (Qadir et al. 2014). The total biomass accumulation and distribution were observed to be decreased in Russian knapweed (Rasouli-Sadaghiani et al. 2019) and M lupulina (Jian et al. 2019) due to severe oxidative stress and root damage caused by $\mathrm{Cd}$ stress. On contrary, our results showed that B.s enhanced the total biomass in both wheat varieties. Therefore, the increased plant growth and biomass production, and distribution is directly correlated with PGPR applications in Eruca sativa under Cd stress (Kamran et al. 2015). (Treesubsuntorn et al. 2018) reaffirms our study, who described that $B$. subtilis and $B$. cereus increased root and shoot biomass when inoculated to $O$. sativa exposed to $\mathrm{Cd}$ toxicity. The possible explanation for increasing biomass accumulation and distribution could be the solubilization of organic minerals from soil towards plants organs, phytoremediation of heavy metals, metal resistance ability of PGPR and the regulation of hormonal production require for plant resistant to heavy metals (Jian et al. 2019; Khanna et al. 2019). Therefore, the PGPR have widely being used to improve the plant growth under various types of environmental stresses.

Chlorophyll as a major component of chloroplast is efficiently associated with plant photosynthetic ability whereas, $\mathrm{Cd}$ and rest of the heavy metals negatively affected the chlorophylls and caused chlorosis in leaves (Rizwan et al. 2016a). Several types of heavy metals such as $\mathrm{Cd}, \mathrm{Zn}, \mathrm{Cu}, \mathrm{Hg}$ and $\mathrm{Pb}$ 
induce toxicity to cell wall and thylakoid membrane integrity which lead to the inhibition of enzymes i.e Rubisco, chlorophyll synthase, involved in the synthesis of chlorophyll and resulting in the degradation of chlorophylls (Hashem 2014). (Rascio et al. 2008) stayed with our results who reported that Cd reduced the $\mathrm{Chl} \mathrm{a}, \mathrm{b}$ and $\mathrm{a}+\mathrm{b}$ content in rice. The photosynthates produced by plants with the help of chlorophyll directly linked with increase in plant biomass production whereas, decline in chlorophylls leads to the lower biomass production influenced by Cd stress (Khanna et al. 2019). The increase in nitrogen content an important molecule of chlorophyll structure, was observed in PGPR inoculated M.lupulina which is associated with more production of plant biomass under heavy metal stress (Jian et al. 2019). Moreover, the $\mathrm{Cd}$ stress severely affected the membrane permeability and enhanced the protein degradation in B.juncea (Ahmad et al. 2015). However, our results are in line with (Pramanik et al. 2018) who revealed that Enterobacter species has stimulated the growth and improved the chlorophyll content in Oryza sativa seedlings by reducing the toxicity of $\mathrm{Cd}$ stress.

In our study, the Cd treatment significantly decreased the water potential, osmotic potential and LRWC in both wheat varieties while the highest values for these parameters was observed under PGPR application. Cd stress in the soil decreased the microbial community and damaged the root tips to reduce the uptake of water and disturb the water balance of cells in leaf resulting in the reduction of stomatal conductance and transpiration rate (Qadir et al. 2014). Consequently, this is directly linked with decline in chloroplast amount as well as cell enlargement and ultimately reduced the plant growth and biomass formation (Rucińska-Sobkowiak 2016). In addition, Cd reduced the surface area of cells that absorb water indicating the disturbance of water balance (Sun et al. 2016). However, the PGPR improves the LRWC and water potential in different plant species exposed to different types of environmental stresses (Naveed et al. 2014). It is reported that PGPR improves the stomatal aperture to uptake more water via roots and enhances the stomatal conductance as compared to non-PGPR inoculated plants (Vejan et al. 2016). (Ahmad et al. 2016) described that PGPR enhanced the water uptake, RWC and membrane stability in the leaf of maize plant under Cd stress which support our study. Moreover, PGPR efficiently improved the tolerance ability of plants exposed to various environmental stresses including heavy metals and increased the yield of plant (Enebe and Babalola 2018).

It is depicted that the effect of $\mathrm{Cd}$ is dose dependent that varies with its concentration, duration of exposure and the nature of plant species at different growth stages (Hussain et al. 2019) thus, the response of NARC-2009 was found better than NARC-2011 on exposure to different levels of Cd. Besides, the PGPR enhanced the plant efficiently alone or with Cd treatment as shown in (Figure.8). Overall, it is estimated that $\mathrm{Cd}$ stress at all levels severely impacted the growth of both wheat varieties while the inoculation with PGPR reduced the Cd toxicity and improved plant growth attributes. However, further studies are needed to find out the actual mechanism of $\mathrm{Cd}$ toxicity in plants at molecular level with the application of PGPR.

\section{Declarations}

\section{Ethics approval and consent to participate}


This article does not contain any studies with human and animal participants. Consent to participate: Not applicable.

\section{Consent for publication}

Not applicable.

\section{Availability of data and material}

All the analysed data for this study are included in this article. Conclusions of the current study is included in this article.

\section{Competing interests}

Authors declare that there is no conflict of interest.

\section{Funding}

The financial support from the Modern Agro-industry Technology Research System (CARS-34) and the Sichuan Province Breeding Research grant (2016NYZ0039) and Modern Agricultural Industry System Sichuan Forage Innovation Team.

\section{Authors' contributions}

Conceptualization, I.K., S.A.A. and A.R.; methodology, M.A.R., I.K., R.T. and M.A.; formal analysis, S.A.A., G.A.S. and N.A.; investigation, L.H., M.B. and A.K.; writing-original draft preparation, I.K., S.A.A.; writingreview and editing, L.H., M.R,. M.S. and S.A.A.; funding acquisition, L.H. All authors have read and agreed to the published version of the manuscript.

\section{Acknowledgements}

IK's thanks to Mian Khan, Manzoor Bibi, Loving brothers for their prayers and guidance, to Associate Professor Dr Muhammad Arshad for his expert advice throughout this challenging research project.

\section{References}

1. Ahemad M, Kibret M (2014) Mechanisms and applications of plant growth promoting rhizobacteria: current perspective. Journal of King saud University-science 26(1):1-20

2. Ahmad I, Akhtar MJ, Asghar HN, Ghafoor U, Shahid M (2016) Differential effects of plant growthpromoting rhizobacteria on maize growth and cadmium uptake. J Plant Growth Regul 35(2):303315

3. Ahmad P, Sarwat M, Bhat NA, Wani MR, Kazi AG, Tran L-SP (2015) Alleviation of cadmium toxicity in Brassica juncea L.(Czern. \& Coss.) by calcium application involves various physiological and 
biochemical strategies. PloS one 10(1)

4. Curtis T, Halford N (2014) Food security: the challenge of increasing wheat yield and the importance of not compromising food safety. Annals of applied biology 164(3):354-372

5. Enebe MC, Babalola $O O$ (2018) The influence of plant growth-promoting rhizobacteria in plant tolerance to abiotic stress: a survival strategy. Appl Microbiol Biotechnol 102(18):7821-7835

6. FAO PCPDB, Electronic Resource under (assed,

7. Gupta P, Kumar V, Usmani Z, Rani R, Chandra A (2018) Phosphate solubilization and chromium (VI) remediation potential of Klebsiella sp. strain CPSB4 isolated from the chromium contaminated agricultural soil. Chemosphere 192:318-327

8. Harris NS, Taylor GJ (2013) Cadmium uptake and partitioning in durum wheat during grain filling. BMC plant biology 13(1):103

9. Hashem H (2014) Cadmium toxicity induces lipid peroxidation and alters cytokinin content and antioxidant enzyme activities in soybean. Botany 92(1):1-7

10. Hussain A, Ali S, Rizwan M, ur Rehman MZ, Javed MR, Imran M, Chatha SAS, Nazir R (2018) Zinc oxide nanoparticles alter the wheat physiological response and reduce the cadmium uptake by plants. Environ Pollut 242:1518-1526

11. Hussain A, Rizwan M, Ali Q, Ali S (2019) Seed priming with silicon nanoparticles improved the biomass and yield while reduced the oxidative stress and cadmium concentration in wheat grains. Environ Sci Pollut Res 26(8):7579-7588

12. Jian L, Bai X, Zhang H, Song X, Li Z (2019) Promotion of growth and metal accumulation of alfalfa by coinoculation with Sinorhizobium and Agrobacterium under copper and zinc stress. PeerJ 7:e6875

13. Kamran MA, Syed JH, Eqani SAMAS, Munis MFH, Chaudhary HJ (2015) Effect of plant growthpromoting rhizobacteria inoculation on cadmium (Cd) uptake by Eruca sativa. Environ Sci Pollut Res 22(12):9275-9283

14. Keller C, Rizwan M, Davidian J-C, Pokrovsky O, Bovet N, Chaurand P, Meunier J-D (2015) Effect of silicon on wheat seedlings (Triticum turgidum L.) grown in hydroponics and exposed to 0 to $30 \mu \mathrm{M}$ Cu. Planta 241(4):847-860

15. Khanna K, Jamwal VL, Gandhi SG, Ohri P, Bhardwaj R (2019) Metal resistant PGPR lowered Cd uptake and expression of metal transporter genes with improved growth and photosynthetic pigments in Lycopersicon esculentum under metal toxicity. Scientific reports 9(1):1-14

16. Lichtenthaler HK (1987) [34] Chlorophylls and carotenoids: pigments of photosynthetic biomembranes Methods in enzymology. vol 148. Elsevier, pp 350-382

17. Liu L, Li J, Yue F, Yan X, Wang F, Bloszies S, Wang Y (2018) Effects of arbuscular mycorrhizal inoculation and biochar amendment on maize growth, cadmium uptake and soil cadmium speciation in Cd-contaminated soil. Chemosphere 194:495-503 
18. Mallick I, Bhattacharyya C, Mukherji S, Dey D, Sarkar SC, Mukhopadhyay UK, Ghosh A (2018) Effective rhizoinoculation and biofilm formation by arsenic immobilizing halophilic plant growth promoting bacteria (PGPB) isolated from mangrove rhizosphere: a step towards arsenic rhizoremediation. Science of The Total Environment 610:1239-1250

19. Mesa-Marín J, Del-Saz NF, Rodríguez-Llorente ID, Redondo-Gómez S, Pajuelo E, Ribas-Carbó M, Mateos-Naranjo E (2018) PGPR reduce root respiration and oxidative stress enhancing spartina maritima root growth and heavy metal rhizoaccumulation. Frontiers in plant science 9:1500

20. Mesa J, Rodríguez-Llorente ID, Pajuelo E, Piedras JMB, Caviedes MA, Redondo-Gómez S, MateosNaranjo E (2015) Moving closer towards restoration of contaminated estuaries: bioaugmentation with autochthonous rhizobacteria improves metal rhizoaccumulation in native Spartina maritima. J Hazard Mater 300:263-271

21. Mishra V, Mishra RK, Dikshit A, Pandey AC (2014) Interactions of nanoparticles with plants: an emerging prospective in the agriculture industry Emerging technologies and management of crop stress tolerance. Elsevier, pp 159-180

22. Naeem A, Saifullah, Rehman MZ-u, Akhtar T, Ok YS, Rengel Z (2016) Genetic variation in cadmium accumulation and tolerance among wheat cultivars at the seedling stage. Commun Soil Sci Plant Anal 47(5):554-562

23. Naveed M, Hussain MB, Zahir ZA, Mitter B, Sessitsch A (2014) Drought stress amelioration in wheat through inoculation with Burkholderia phytofirmans strain PsJN. Plant Growth Regul 73(2):121-131

24. Pramanik K, Mitra S, Sarkar A, Soren T, Maiti TK (2018) Characterization of a Cd2+-resistant plant growth promoting rhizobacterium (Enterobacter $\mathrm{sp}$.) and its effects on rice seedling growth promotion under Cd2+-stress in vitro. Agriculture Natural Resources 52(3):215-221

25. Qadir S, Jamshieed S, Rasool S, Ashraf M, Akram NA, Ahmad P (2014) Modulation of plant growth and metabolism in cadmium-enriched environments Reviews of environmental contamination and toxicology. Springer, pp 51-88

26. Rajkumar M, Ma Y, Freitas H (2013) Improvement of Ni phytostabilization by inoculation of $\mathrm{Ni}$ resistant Bacillus megaterium SR28C. Journal of environmental management 128:973-980

27. Rascio N, Dalla Vecchia F, La Rocca N, Barbato R, Pagliano C, Raviolo M, Gonnelli C, Gabbrielli R (2008) Metal accumulation and damage in rice (cv. Vialone nano) seedlings exposed to cadmium. Environ Exp Bot 62(3):267-278

28. Rasouli-Sadaghiani M, Barin M, Khodaverdiloo H, Moghaddam SS, Damalas C, Kazemalilou S (2019) Arbuscular mycorrhizal fungi and rhizobacteria promote growth of Russian knapweed (Acroptilon repens L.) in a Cd-contaminated soil. J Plant Growth Regul 38(1):113-121

29. Rizwan M, Ali S, Abbas T, Zia-ur-Rehman M, Hannan F, Keller C, Al-Wabel MI, Ok YS (2016a) Cadmium minimization in wheat: a critical review. Ecotoxicol Environ Saf 130:43-53

30. Rizwan M, Ali S, Ali B, Adrees M, Arshad M, Hussain A, ur Rehman MZ, Waris AA (2019) Zinc and iron oxide nanoparticles improved the plant growth and reduced the oxidative stress and cadmium concentration in wheat. Chemosphere 214:269-277 
31. Rizwan M, Ali S, Qayyum MF, Ok YS, Adrees M, Ibrahim M, Zia-ur-Rehman M, Farid M, Abbas F (2017) Effect of metal and metal oxide nanoparticles on growth and physiology of globally important food crops: A critical review. J Hazard Mater 322:2-16

32. Rizwan M, Ali S, ur Rehman MZ, Rinklebe J, Tsang DC, Bashir A, Maqbool A, Tack F, Ok YS (2018) Cadmium phytoremediation potential of Brassica crop species: a review. Science of The Total Environment 631:1175-1191

33. Rizwan M, Meunier J-D, Davidian J-C, Pokrovsky O, Bovet N, Keller C (2016b) Silicon alleviates Cd stress of wheat seedlings (Triticum turgidum L. cv. Claudio) grown in hydroponics. Environ Sci Pollut Res 23(2):1414-1427

34. Rucińska-Sobkowiak R (2016) Water relations in plants subjected to heavy metal stresses. Acta Physiol Plant 38(11):257

35. Sairam R, Srivastava G, Agarwal S, Meena R (2005) Differences in antioxidant activity in response to salinity stress in tolerant and susceptible wheat genotypes. Biol Plant 49(1):85

36. Seifter S, Dayton S, Novic B, Muntwyler E (1950) The estimation of glycogen with the anthrone reagent. Arch Biochem 25:191-200

37. Shoeva OY, Khlestkina E (2018) Anthocyanins participate in the protection of wheat seedlings against cadmium stress. Cereal Research Communications 46(2):242-252

38. Sun Y, Sun G, Xu Y, Liu W, Liang X, Wang L (2016) Evaluation of the effectiveness of sepiolite, bentonite, and phosphate amendments on the stabilization remediation of cadmium-contaminated soils. Journal of environmental management 166:204-210

39. Treesubsuntorn C, Dhurakit $P$, Khaksar G, Thiravetyan $P(2018)$ Effect of microorganisms on reducing cadmium uptake and toxicity in rice (Oryza sativa L.). Environ Sci Pollut Res 25(26):25690-25701

40. Turk H, Erdal S (2015) Melatonin alleviates cold-induced oxidative damage in maize seedlings by upregulating mineral elements and enhancing antioxidant activity. J Plant Nutr Soil Sci 178(3):433439

41. Turner NC (1986) Crop water deficits: a decade of progress Advances in agronomy. vol 39. Elsevier, pp 1-51

42. Turner NC, Begg JE (1981) Plant-water relations and adaptation to stress. Plant soil 58(1-3):97-131

43. Turner R, Marshall C (1972) The accumulation of zinc by subcellular fractions of roots of Agrostis tenuis Sibth. in relation to zinc tolerance. New Phytol 71(4):671-676

44. Vejan P, Abdullah R, Khadiran T, Ismail S, Nasrulhaq Boyce A (2016) Role of plant growth promoting rhizobacteria in agricultural sustainability-a review. Molecules 21(5):573

45. Verma K, Shekhawat G, Sharma A, Mehta S, Sharma V (2008) Cadmium induced oxidative stress and changes in soluble and ionically bound cell wall peroxidase activities in roots of seedling and 3-4 leaf stage plants of Brassica juncea (L.) czern. Plant Cell Rep 27(7):1261-1269

46. Wang Q, Chen L, He L-Y, Sheng X-F (2016) Increased biomass and reduced heavy metal accumulation of edible tissues of vegetable crops in the presence of plant growth-promoting 


\section{Unsectioned Tables}

Table.1. Analysis of the soil.

\begin{tabular}{|ll|}
\hline $\mathbf{p H}$ & 7.45 \\
\hline EC dSm $^{-1}$ & 1.28 \\
\hline Organic matter (\%) & 1.92 \\
\hline Phosphorus $(\mathrm{mg} / \mathrm{kg})$ & 6.2 \\
\hline Potassium $(\mathrm{mg} / \mathrm{kg})$ & 100 \\
\hline $\mathrm{Zn}(\mathrm{mg} / \mathrm{kg})$ & 1.04 \\
\hline $\mathrm{Cu}(\mathrm{mg} / \mathrm{kg})$ & 0.71 \\
\hline $\mathrm{Mn}(\mathrm{mg} / \mathrm{kg})$ & 2.64 \\
\hline Fe $(\mathrm{mg} / \mathrm{kg})$ & 2.95 \\
\hline $\mathrm{Cd}(\mathrm{mg} / \mathrm{kg})$ & 4.36 \\
\hline Saturation $(\%)$ & 33 \\
\hline
\end{tabular}

Figures
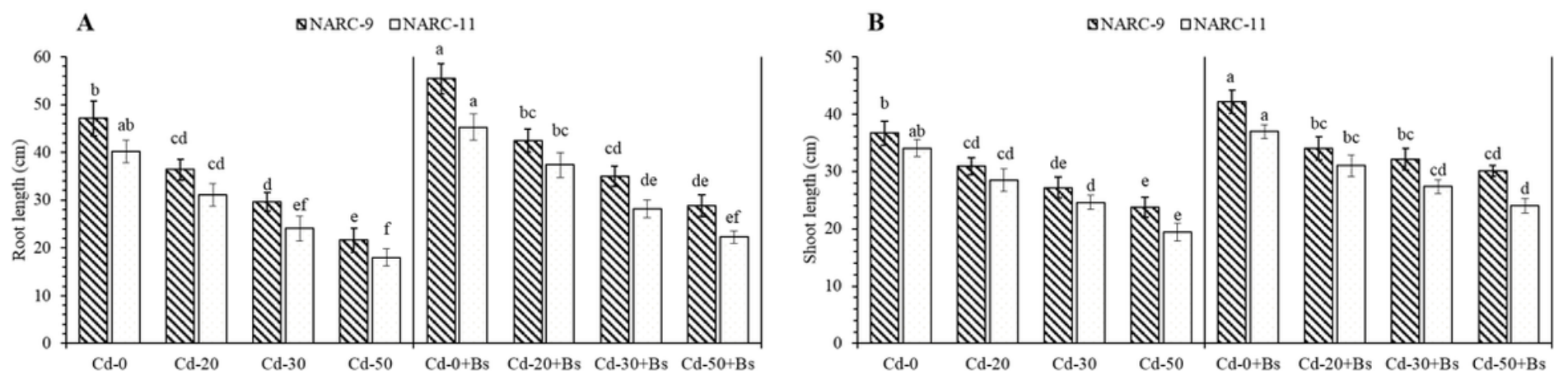

Figure. 1. Morphological attributes of two wheat varieties i.e NARC-9 and NARC-11 inoculated with Bacillus siamensis under different cadmium treatments. (A) Root length (B) Shoot length at 30 days after sowing (DAS). Data are expressed as the average of three replicates. Bars show \pm SE within a bar and lowercase letters show a significant difference at 0.05 level.

\section{Figure 1}


$\mathbf{A}$

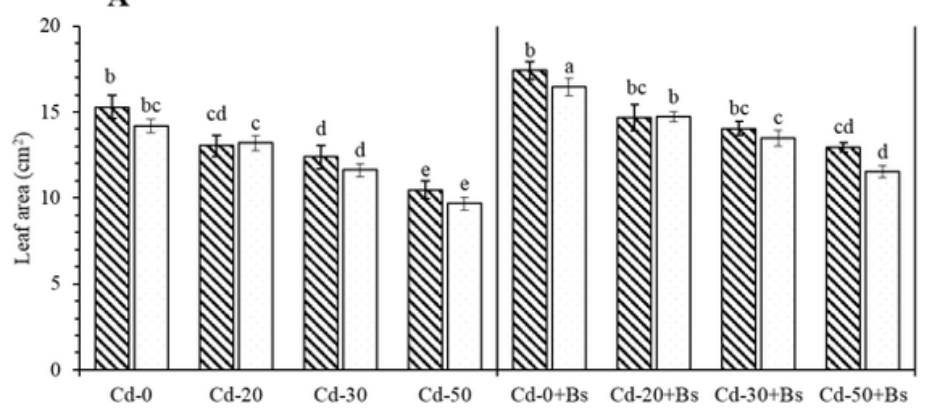

B

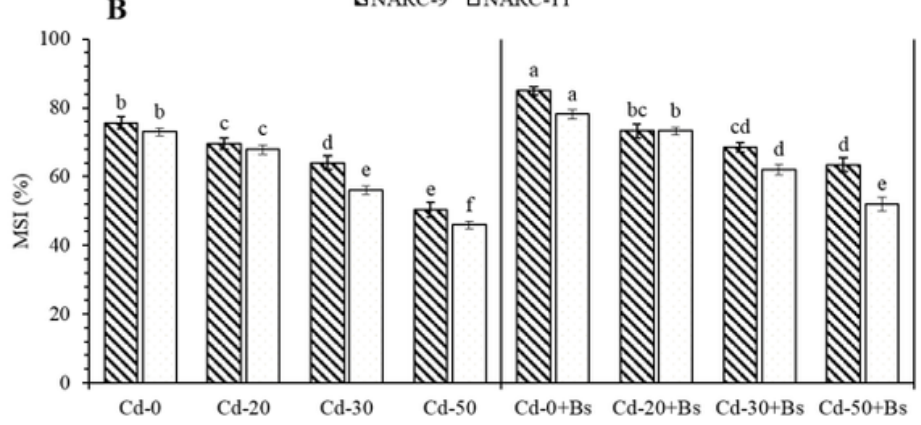

Figure. 2. Leaf traits of two wheat varieties i.e NARC-9 and NARC-11 inoculated with Bacillus siamensis under different cadmium treatments. (A) Leaf area (B) Membrane stability index (MSI) at 30 days after sowing (DAS). Data are expressed as the average of three replicates. Bars show \pm SE within a bar and lowercase letters show a significant difference at 0.05 level.

Figure 2

A

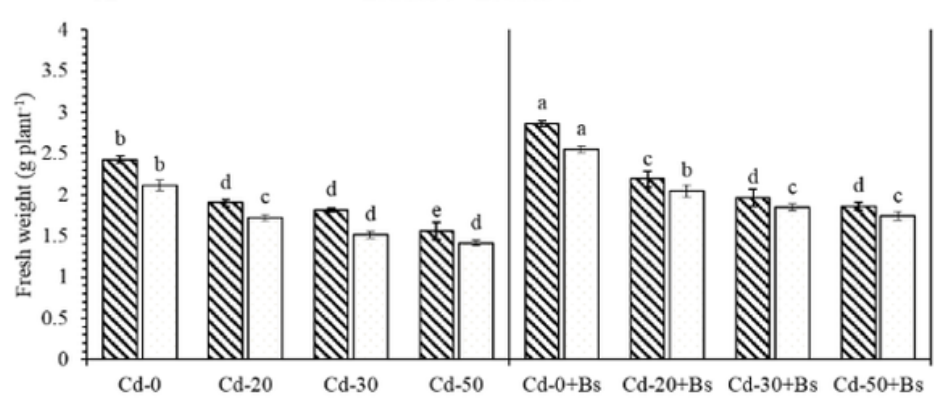

B

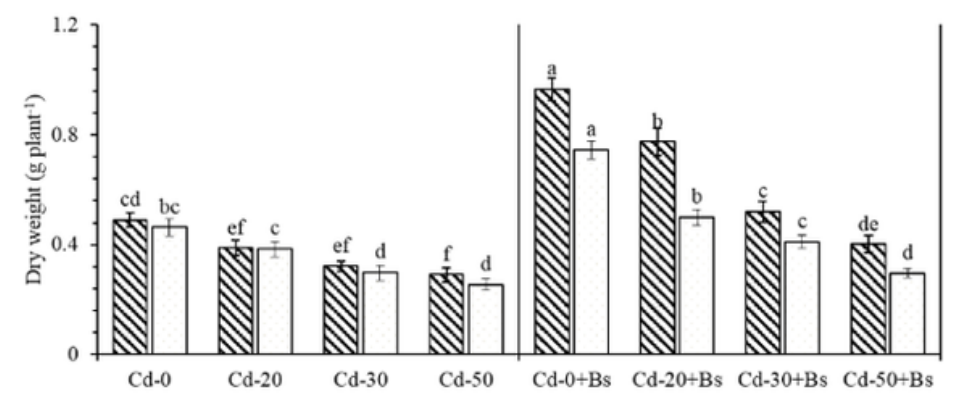

Figure. 3. Biomass of two wheat varieties i.e NARC-9 and NARC-11 inoculated with Bacillus siamensis under different cadmium treatments. (A) Fresh weight (B) Dry weight at 30 days after sowing (DAS). Data are expressed as the average of three replicates. Bars show \pm SE within a bar and lowercase letters show a significant difference at 0.05 level.

\section{Figure 3}



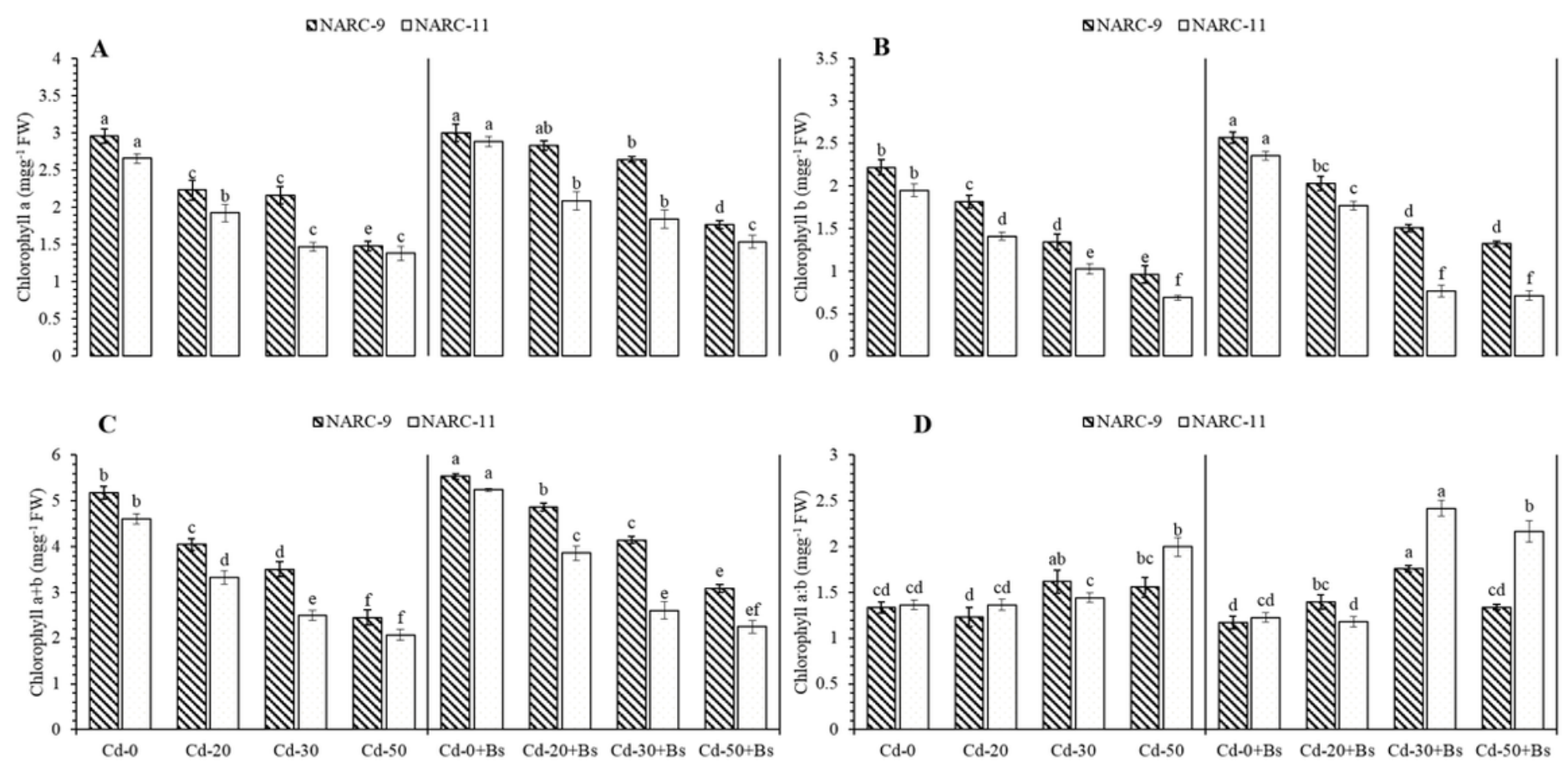

Figure. 4. Photosynthetic pigments of two wheat varieties i.e NARC-9 and NARC-11 inoculated with Bacillus siamensis under different cadmium treatments. (A) Chlorophyll a (B) Chlorophyll b (C) Chlorophyll (a + b) (D) Chlorophyll (a : b), at 30 days after sowing (DAS). Data are expressed as the average of three replicates. Bars show \pm SE within a bar and lowercase letters show a significant difference at 0.05 level.

Figure 4 
QNARC-9 $\quad$ QNARC-11

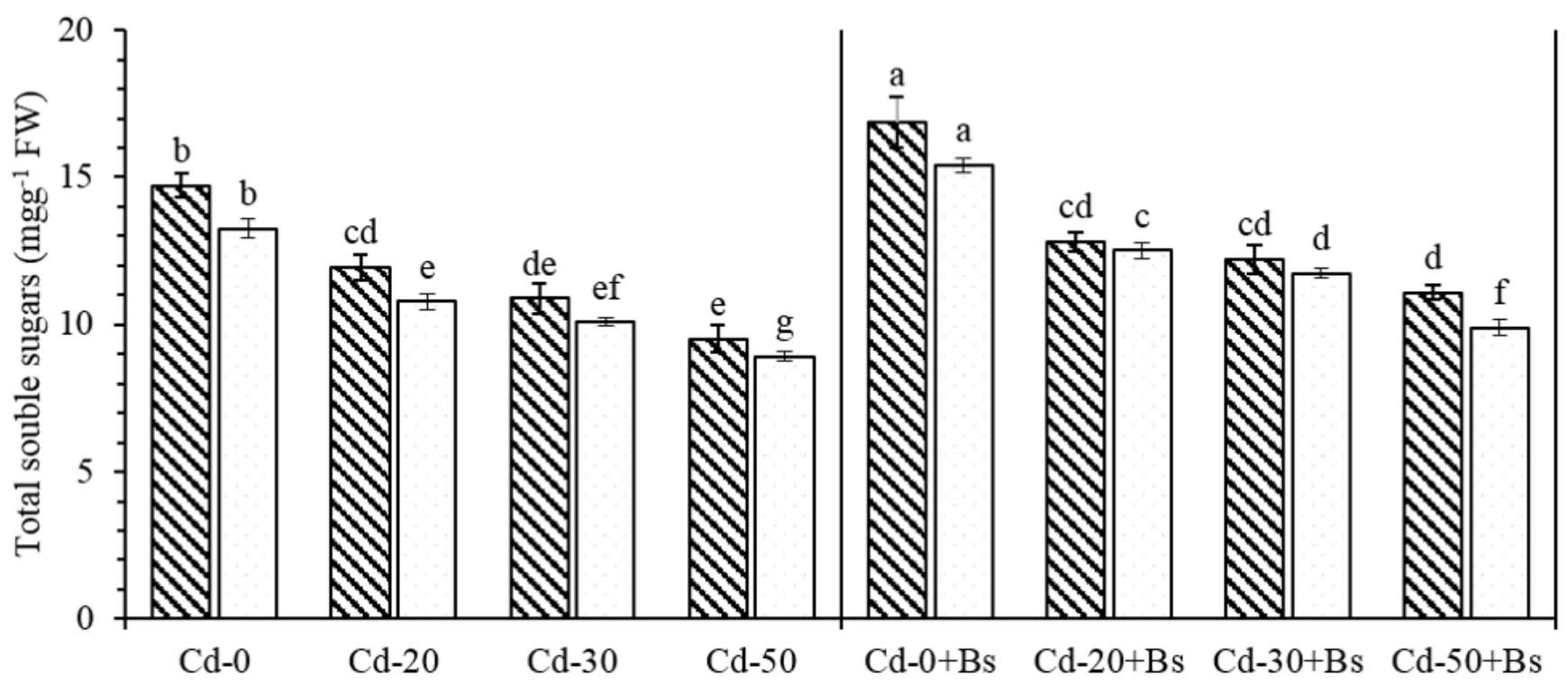

Figure. 5. Total soluble sugars content of two wheat varieties i.e NARC-9 and NARC-11 inoculated with Bacillus siamensis under different cadmium treatments at 30 days after sowing (DAS). Data are expressed as the average of three replicates. Bars show \pm SE within a bar and lowercase letters show a significant difference at 0.05 level.

Figure 5
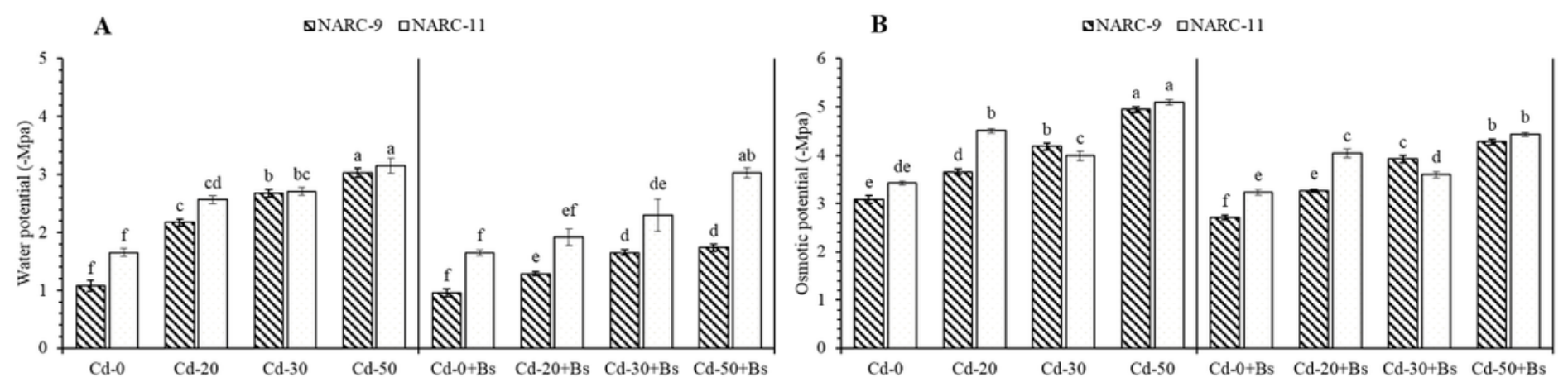

Figure. 6. Water status of two wheat varieties i.e NARC-9 and NARC-11 inoculated with Bacillus siamensis under different cadmium treatments (A) Water potential (B) Osmotic potential, at 30 days after sowing (DAS). Data are expressed as the average of three replicates. Bars show \pm SE within a bar and lowercase letters show a significant difference at 0.05 level.

Figure 6 
QNARC-9 aNARC-11

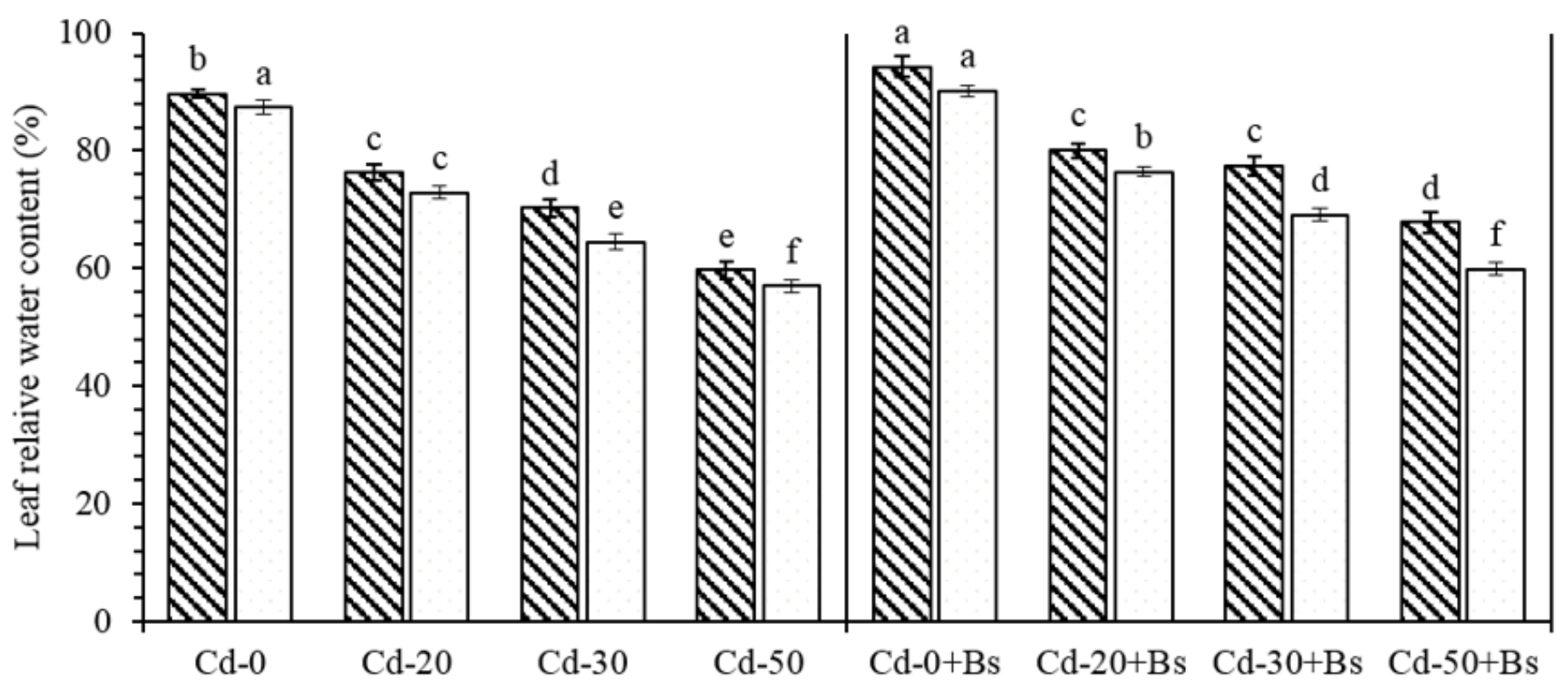

Figure. 7. Leaf relative water content of two wheat varieties i.e NARC-9 and NARC-11 inoculated with Bacillus siamensis under different cadmium treatments at 30 days after sowing (DAS). Data are expressed as the average of three replicates. Bars show $\pm \mathrm{SE}$ within a bar and lowercase letters show a significant difference at 0.05 level.

Figure 7
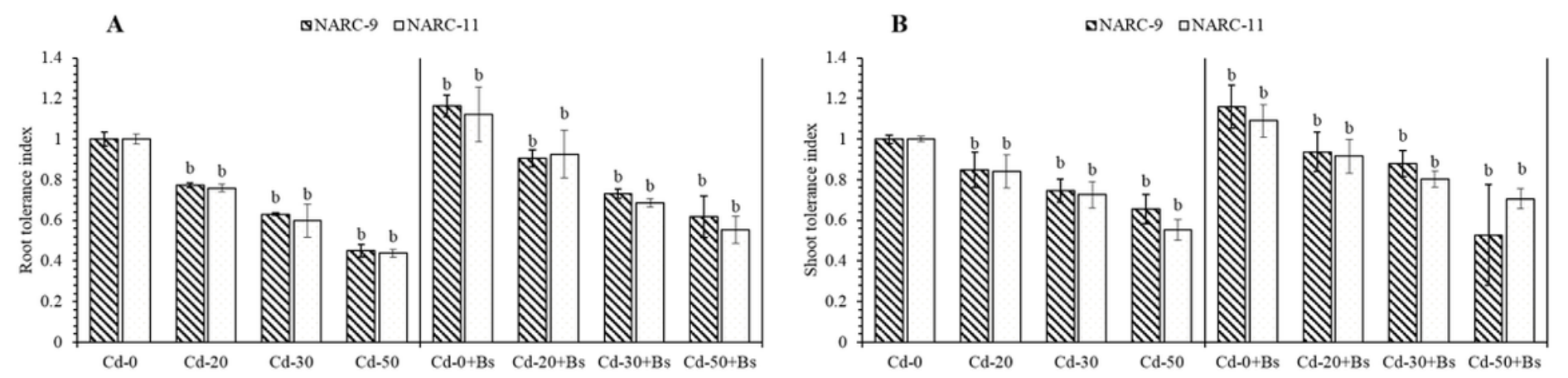

Figure. 8. Tolerance index of two wheat varieties i.e NARC-9 and NARC-11 inoculated with Bacillus siamensis under different cadmium treatments (A) Root tolerance index (B) Shoot tolerance index, at 30 days after sowing (DAS). Data are expressed as the average of three replicates. Bars show $\pm \mathrm{SE}$ within a bar and lowercase letters show a significant difference at 0.05 level. 